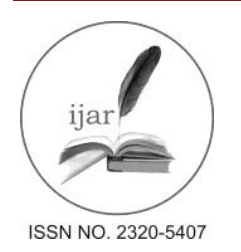

\section{Journal homepage:http://www.journalijar.com Journal DOI:10.21474/IJAR01}

\section{RESEARCH ARTICLE}

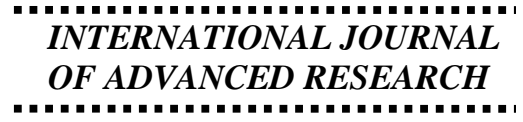

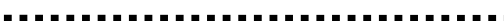

\title{
ON RHEOLOGICAL BEHAVIOR OF AQUEOUS POLYACRYLAMIDE SOLUTION.I-EMPIRICAL RELATION OF THE VISCOSITY AS A FUNCTION OF CONCENTRATION AND SHEAR RATE.
}

\author{
I. M. Shabaka', M. Abdel Wahab ${ }^{2}$, S. E. E. Hamza' ${ }^{2}$, Mostafa Y. El-Bakry ${ }^{2}$ and S. Hashem ${ }^{3}$. \\ 1. Aerospace Department, Faculty of Engineering, Cairo University, Giza Egypt. \\ 2. Physics Department, Faculty of Science, Benha University, Benha, Egypt. \\ 3. Post graduate Student, Physics Department, Faculty of Science, Benha University, Benha, Egypt
}

\section{Manuscript Info}

Manuscript History:

Received: 12 May 2016

Final Accepted: 13 June 2016

Published Online: July 2016

Key words:

Rheology, Shear rate,

Concentrations, Viscosity,

Polyacrylamide solutions.

*Corresponding Author

I. M. Shabaka.

\begin{abstract}
Polyacrylamide (PAM) solutions are extensively used as chemical additives or Processing aids in the manufacturing of paper and paperboard products. In addition, they have been widely used in enhanced oil recovery. In our paper, an experimental work has been carried out to provide a complete and comprehensive study of the rheological properties of PAM solutions using Brookfield viscometer DV-II. The concentrations of PAM in the tested solutions ranged by weight from 1000 to $5000 \mathrm{ppm}$. The findings resulted in several conclusions regarding the rheological properties of PAM solutions. They have shown a strong shear thinning behavior for all concentrations. Rheological characteristics of aqueous PAM solutions with shear rate ranged between $1.29 \mathrm{~s}^{-1}$ and $64.5 \mathrm{~s}^{-1}$ are investigated. A new proposed correlation for the viscosity of PAM solution as a function of shear rate and concentration has been suggested. The proposed correlation was found to be good fitting with the experimental data.
\end{abstract}

Copy Right, IJAR, 2013.. All rights reserved.

\section{Introduction:-}

A number of rheological studies on PAM have been carried out under different conditions .These studies have shown that PAM solutions possess complex behavior that can restrain industrial uses. In the paper industry, PAM has been used to maintain the efficiency of operation and quality of products. It is effective in increasing fiber bonding and in improving dryStrength (Bird et al., 1987). It has been used in many additional applications including water treatment, mineral processing, dust control and sugar manufacturing. Polyacrylamide is one of the best polymers used as a drag reduction agent and vortex inhibitor due to its flexibility and long chain. The drag reduction is defined by the reduction in pressure drop in the polymer solution relative to the pure solvent alone at the same flow rate [1].

(A. Ait-kadi et al., 1987) have carried out an experimental study to investigate the rheological properties of partially hydrolyzed PAM solutions and reported that the salt had stabilizing effect on the viscosity. This effect is characterized by lower viscosity levels and less shear thinning behavior as salt concentration is increased. (TieQiang et al., 1995) have studied the pipe flow of aqueous PAM solutions by means of nuclear magnetic resonance imaging. They found that, at low flow rate, laminar flow, unsteady motion appears and the mean velocity profile becomes more blunted. For fully turbulent flow, PAM solution shows a typical velocity profile for drag reduction fluids. Polyacrylamide has been used in enhanced oil recovery processes. Oil still in remaining in the earth after a water flood can be recovered from the reservoir by improving the sweep efficiency and/or reducing the interfacial tension between flood-oil. One effective technique to discharge oil at this stage is polymer flooding.

(Lakatos et al., 1995) have studied the effect of carbon dioxide $\left(\mathrm{CO}_{2}\right)$ on the rheological properties and structure of PAM solutions with the aim of using them in enhanced oil recovery. They concluded that high molecular weight PAM must be used in order for the polymer to contact with carbon dioxide. 
(Nasr-El-Din et al., 1995) have studied the interfacial behavior of crude oil in the presence of partially hydrolyzed PAM and reported that, at sodium carbonate concentration less than $0.2 \%$ mass, the interfacial tension did not change with respect to time. Increasing polymer concentration caused slight drop in interfacial tension using sodium carbonate $0.2 \%$ mass. The addition of polymer up to $2000 \mathrm{ppm}$ had no effects on the interfacial tension. Adding sodium carbonate of concentration greater than $0.2 \%$ mass leads to lowering of the interfacial tension.

( Esmail et al.,1998) have reported that the viscosity of PAM solution decrease with temperature. The temperature effect is more pronounced at high shear rates. The flow behavior index " $n$ " is found to be constant for all the PAM concentrations and temperatures. However the fluid consistency index " $k$ " was found to be function of temperature and PAM concentrations.

(Flew et al., 1993) studied the non-Newtonian flow of PAM solutions in porous media and reported that PAM can be used as viscosifying agents in oil field injection, and even very high molecular weight PAM could find applications in the fracture treatment of oil wells. (Durst et al., 1981) have studied the flow of PAM solutions in porous media under various solvent conditions and they found that the maximum increase in pressure drop is mainly dependent on the molecular weight of the polymer. Furthermore, the addition of salt ions to solutions of partially hydrolyzed PAM yields onset behavior previously observed for nonionic polymers.

(Dupuis et al., 1994) demonstrated the rheological properties of solutions of high molecular weight partially hydrolyzed PAM in mixture of glycerol and water. They concluded that its viscosity depends on time. The nonNewtonian viscosity of these solutions was affected by time and showed slight shear thickening. (Branda et al., 1995) researched the influence of glycerol content and the degree of ionization on the negative thixotropy of solutions of partially hydrolyzed PAM. They reported that, the character of negative thixotropy of partially hydrolyzed PAM in aqueous glycerol strongly depends on polymer concentration, glycerol content, and shear rate applied. At low polymer and glycerol concentrations, shear stress and viscosity slowly increase during shearing to a limited value. However, steep increase in shear stress, as well as normal stress, followed by their pronounced oscillations occur at higher concentrations of both components and at higher shear rates.

The basic principle of biopolymer flushing is that, the addition of a biopolymer to the flushing water leads to increased viscosity and capillary number, decreased mobility, and contact with a larger volume of the reservoir (Lake et al., 2008). The viscosity of biopolymer solutions, like that of other polymer solutions, is constant at low shear rate and constant again at high shear rate, whereas the viscosity of air is independent of the shear rate (Picout et al.,2003).

Polyelectrolyte solutions have been studied extensively for both theoretical and experimental purposes. Due to electrostatic interactions between the charged groups along the polyelectrolyte chains, its solutions behaves differently than the neutral polymers for activity coefficients, osmotic coefficients, as well as transport properties like, viscosity, diffusion, etc. (Ghimici L.et al.,1998),( Wu Q. et al.,2009),( Ydens I. et al.,2005)and(Kitano T. et al.,2004).

The viscometric behavior of hydrolyzed PAM-poly (4-vinylpyridine) (AD37-P4VP) mixture in aqueous solution. The result shows that the intermolecular electrostatic associations are favoured by increasing the P4VP concentration. Thus, mixtures rich in P4VP are characterized by a high decrease in the viscosity due to interpolymer complete complexation AD37-P4VP, leading to the totally contraction or collapse of the polymer chains (Mansri A. et al., 2007).

\section{Experimental work:-}

In the present work we study the rheological properties of five different concentrations of PAM (A1210) solutions of molecular weight 12.2 million from Bluwat Company, China. The solutions were prepared by adding a known amount of polymer powder to half liter of distilled water at room temperature $293 \mathrm{~K}$. This study cover the concentration range $1000 \mathrm{ppm}-5000 \mathrm{ppm}$ to investigate the rheological behavior of PAM solutions by using Brookfield viscometer DV-II and all these measurements was at $293^{\circ} \mathrm{k}$. 


\section{Result and discussion:-}

Rheological behavior of 1000 ppm:-

The viscometer has been used for measuring the viscosity of 1000 ppm PAM aqueous solution at different shear rate and the following results have been obtained. The most popular equation represents the so-called power law model formulated by Ostwald and waele was given (Bird et al., 1960)

$$
\eta=k \dot{\gamma}^{n-1}
$$

Where $\eta$ is the viscosity, $\dot{\gamma}$ is the shear rate, kand nare consistency index and flow behavior index, respectively. From Eq. (1), we distinguish three behaviors as a function of the values of $\mathrm{n}$ : when $n=1$, the viscosity of the system is independent of shear rate, the system presents a Newtonian behavior. In the second case $n>1$, the system will exhibit shear-thickening behavior, for $n<1$, a shear thinning behavior is observed.

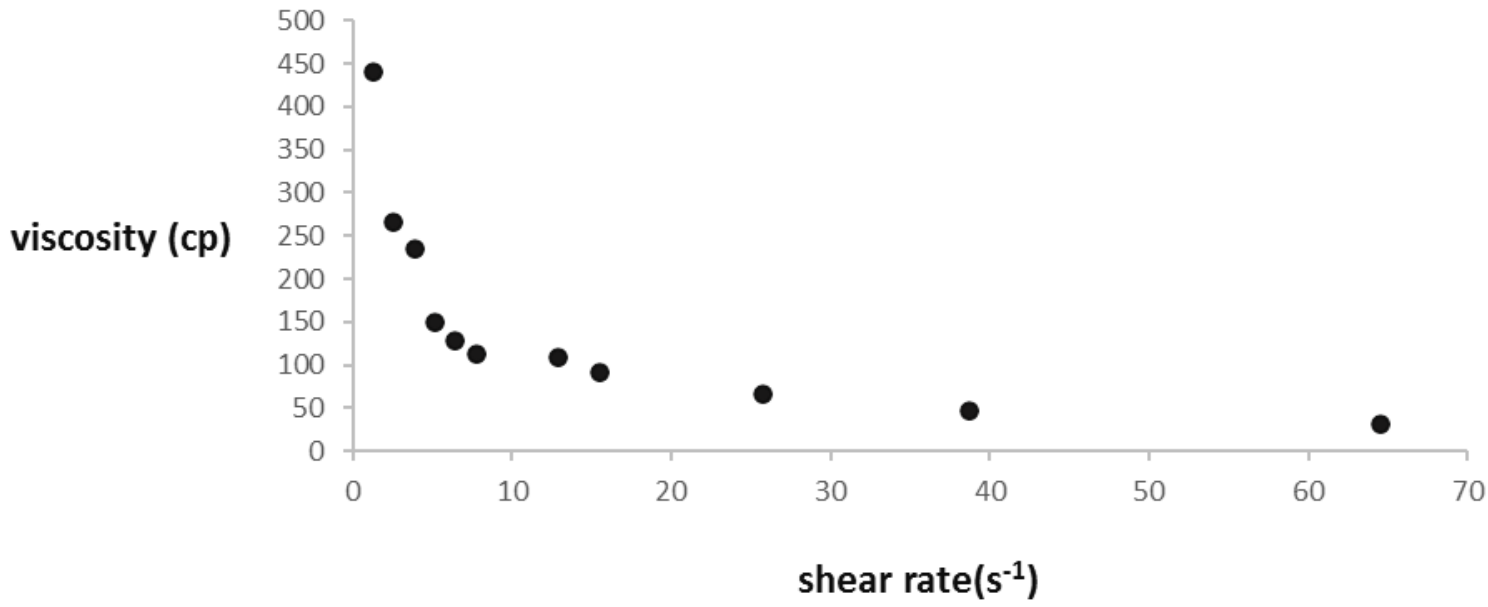

Fig. 1: The relation between viscosity and shear rate for $1000 \mathrm{ppm}$ PAM aqueous solution at $293 \mathrm{~K}$.

In this work, the effect of polymer concentration and shear rate on the viscosity of polymer solution has been investigated experimentally. Different types of expressions for the effect of shear rate was superimposed to fit the experimental data obtained. However, our proposed expression of the polymer solutions viscosity is:

$\eta=489.2 \dot{\gamma}^{-0.64}$.

For the same concentration the viscosity varies exponentially with the shear rate. The drop in viscosity is very sharp as shear rate increases slightly at low levels of shear rate. This sensitivity vanishes rapidly at the higher values of shear rate.

\section{Rheological behavior of 2000 ppm:-}

The viscometer has been used for measuring the viscosity of 2000 ppm PAM aqueous solution at different shear rate and the following results have been obtained:

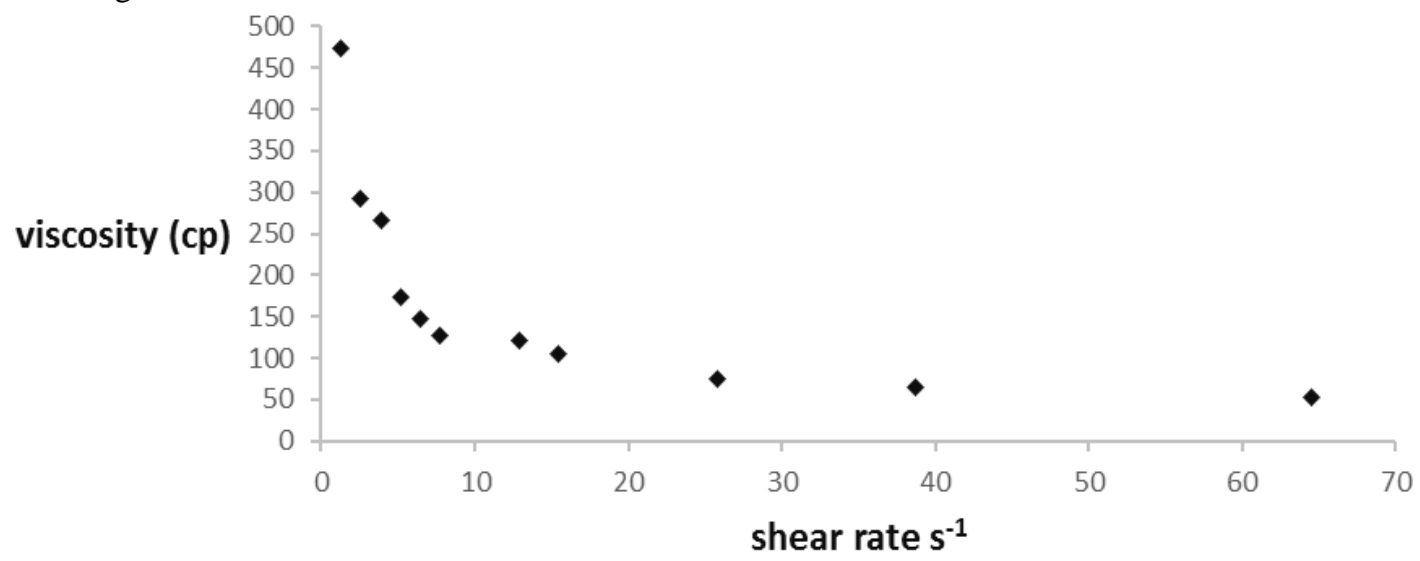

Fig. 2:- The relation between viscosity and shear rate for 2000 ppm PAM aqueous solution. 
Our proposed expression to predict the viscosity of the polymer solution in this case is:

$$
\eta=485.9 \dot{\gamma}^{-0.56} \text {. }
$$

\section{Rheological behavior of 3000 ppm:-}

The viscometer has been used for measuring the viscosity of 3000 ppm PAM aqueous solution at different shear rate and the following results have been obtained:

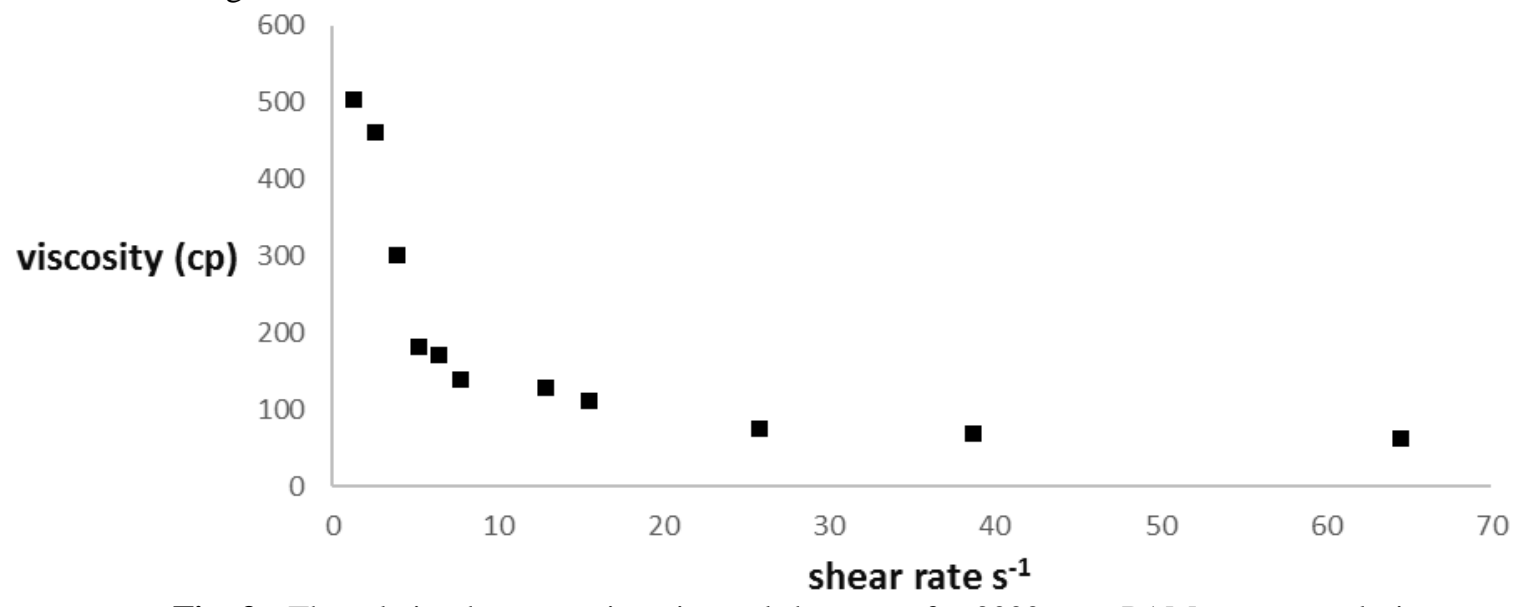

Fig. 3:- The relation between viscosity and shear rate for 3000 ppm PAM aqueous solution.

Our proposed expression to predict the viscosity of the polymer solution in this case is

$$
\eta=585.6 \dot{\gamma}^{-0.59} \text {. }
$$




\section{Rheological behavior of $\mathbf{4 0 0 0}$ ppm:-}

The viscometer has been used for measuring the viscosity of 4000 ppm PAM aqueous solution at different shear rate and the following results have been obtained:

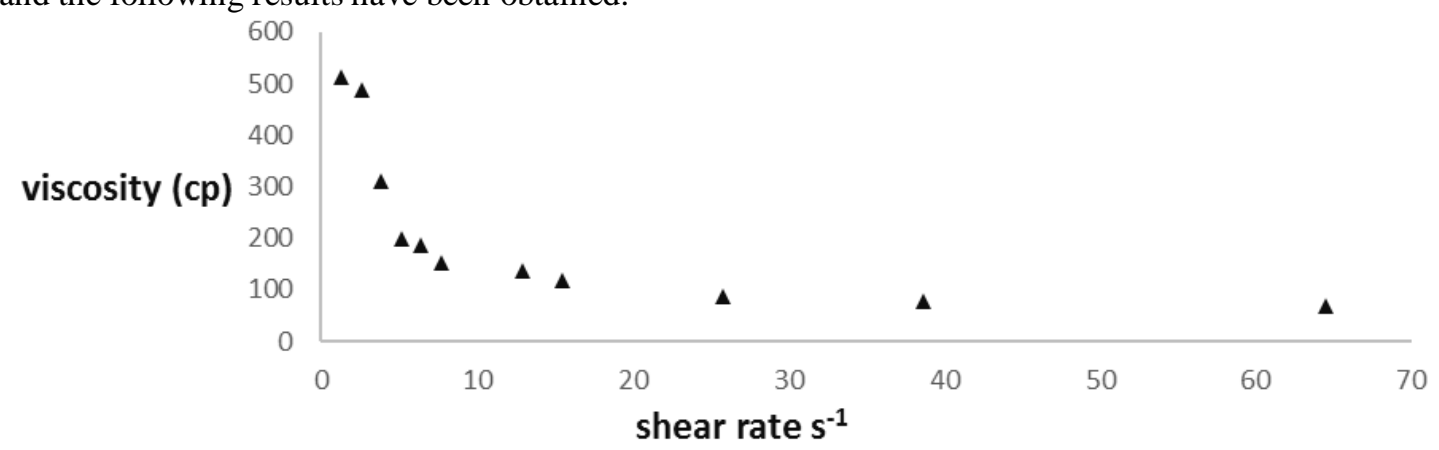

Fig. 4:- The relation between viscosity and shear rate for 4000 ppm PAM aqueous solution.

Our proposed expression to predict the viscosity of the polymer solution in this case is

$\eta=601.7 \dot{\gamma}^{-0.57}$

\section{Rheological behavior of 5000 ppm:-}

The viscometer has been used for measuring the viscosity of 5000 ppm PAM aqueous solution at different shear rate and the following results have been obtained:

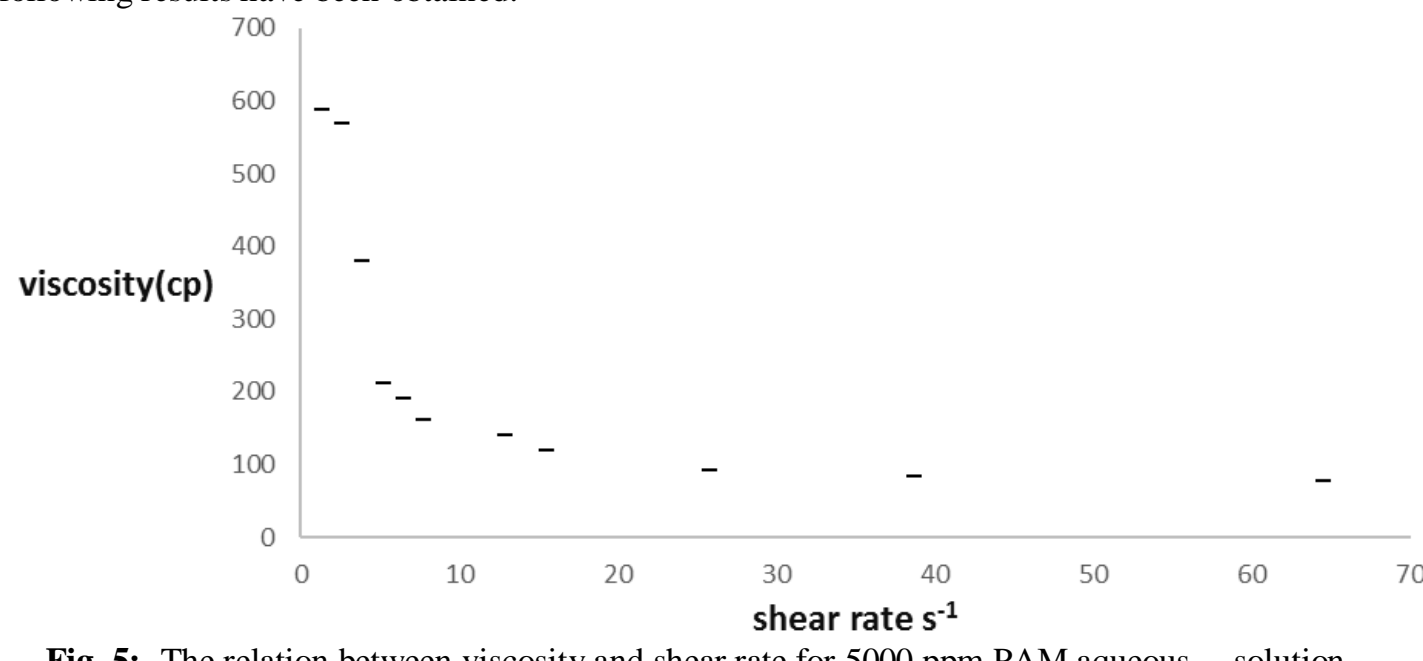

Fig. 5:- The relation between viscosity and shear rate for $5000 \mathrm{ppm}$ PAM aqueous solution.

Our proposed expression to predict the viscosity of the polymer solution in this case is

$\eta=683 \dot{\gamma}^{-0.58}$

\section{Proposed correlation:-}

The analysis the obtained figures shows that, the viscosity increases as the concentration increase. We predict the following equation to describe the relation between the viscosity, concentration and the shear rate of aqueous PAM solution

$$
\eta=460 *(1+1.2 * c) \dot{\gamma}^{\left(-0.58 *(1+c)^{3}\right)}
$$


The comparison between the predicted equation and experimental data :-

The following figures show the relation between the predicted and experimental values of the viscosity versus the shear rate for different concentrations of PAM solutions.

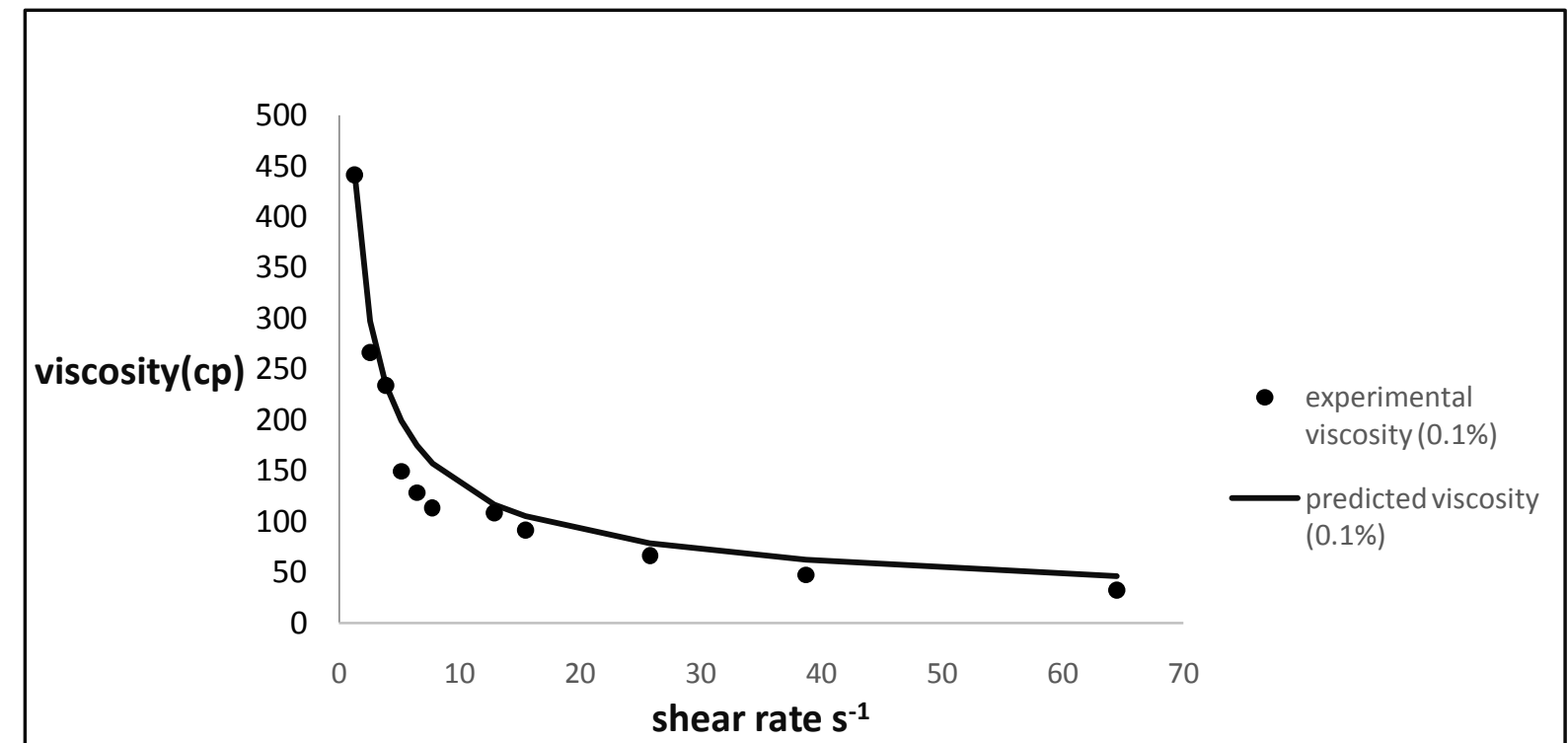

Fig. 6:- The relation between predicted and experimental data for the viscosity versus shear rate for $1000 \mathrm{ppm}$ PAM solution.

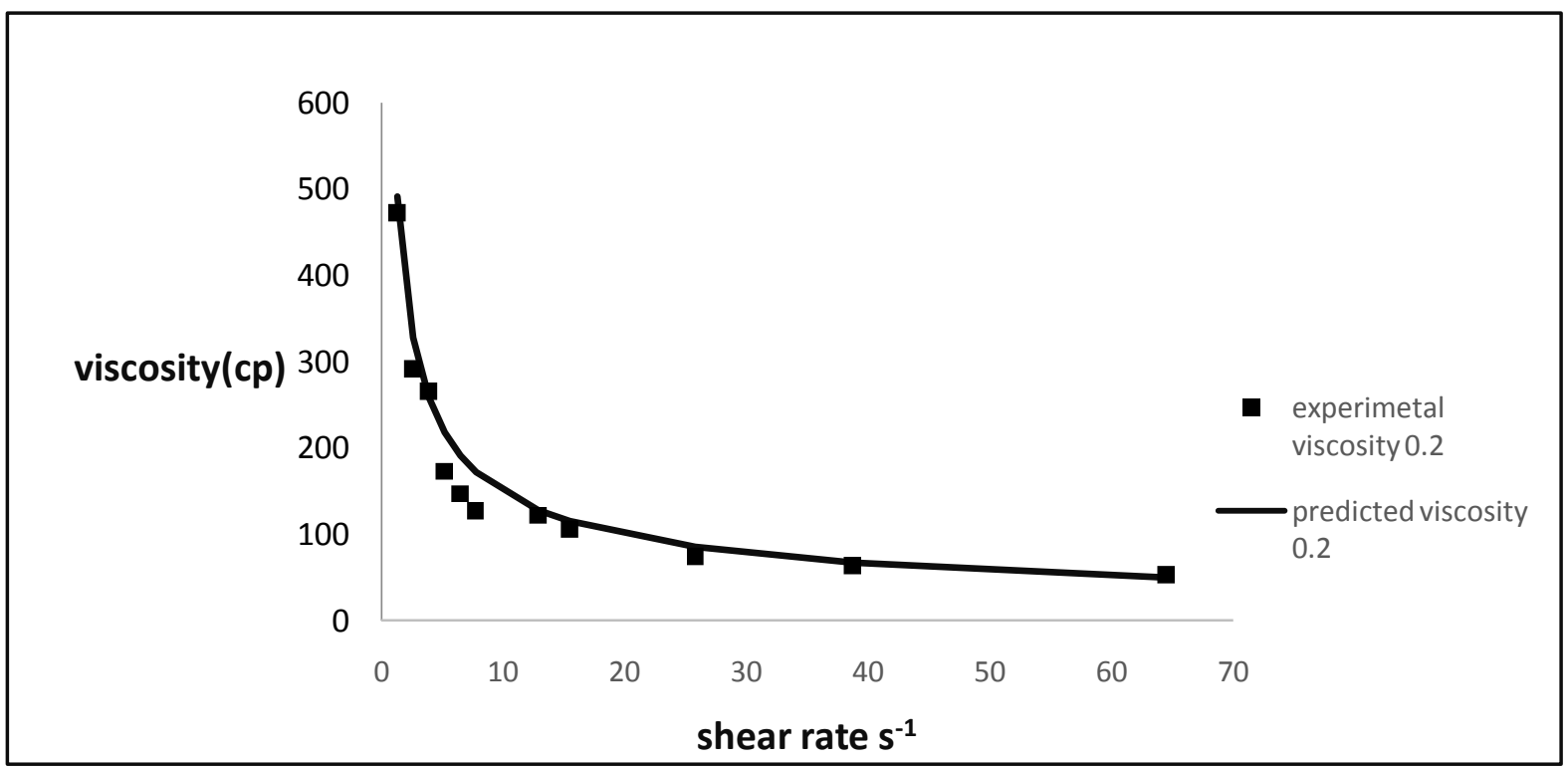

Fig. 7:- The relation between predicted and experimental data for the viscosity versus shear rate for $2000 \mathrm{ppm}$ PAM solution. 


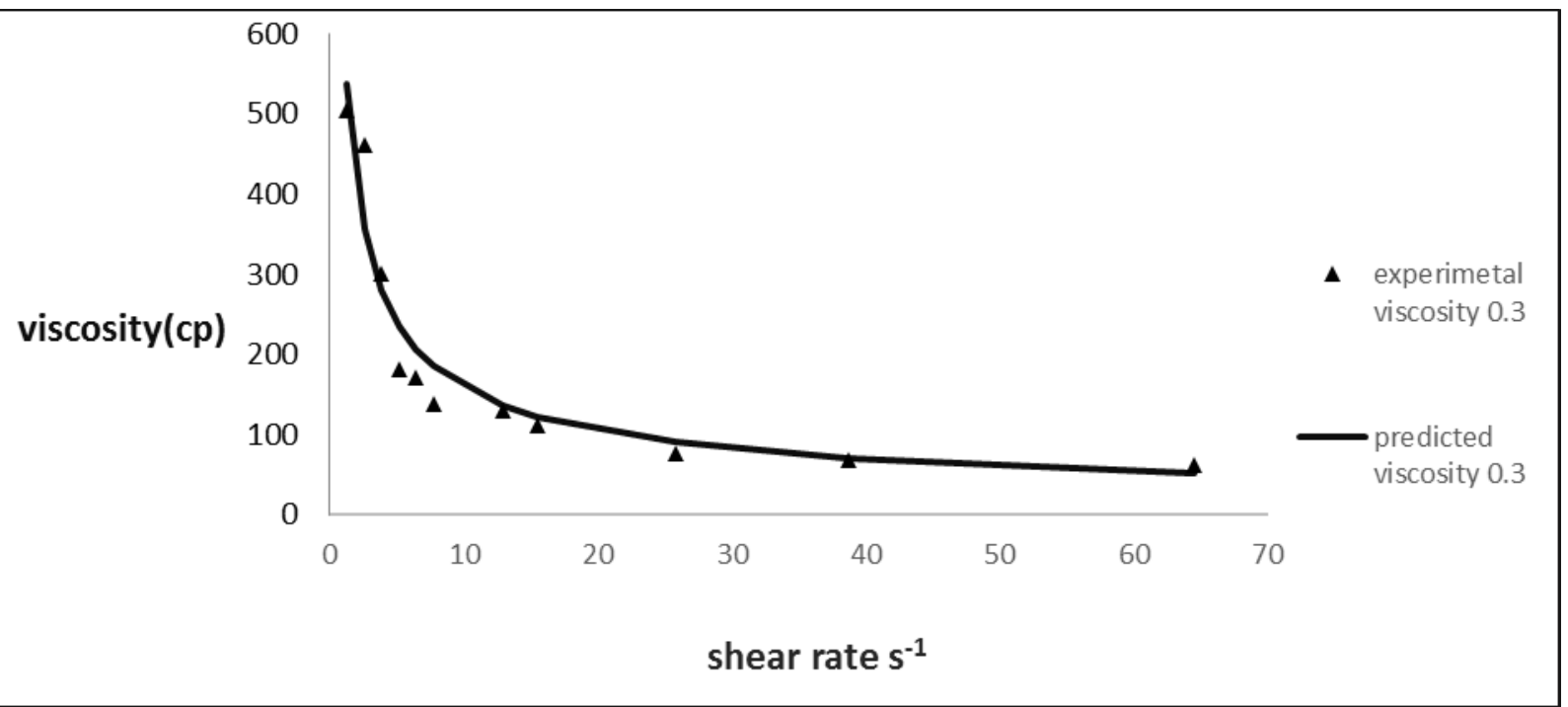

Fig. 8:- shows the relation between predicted and experimental data for the viscosity versus shear rate for $3000 \mathrm{ppm}$ PAM solution.

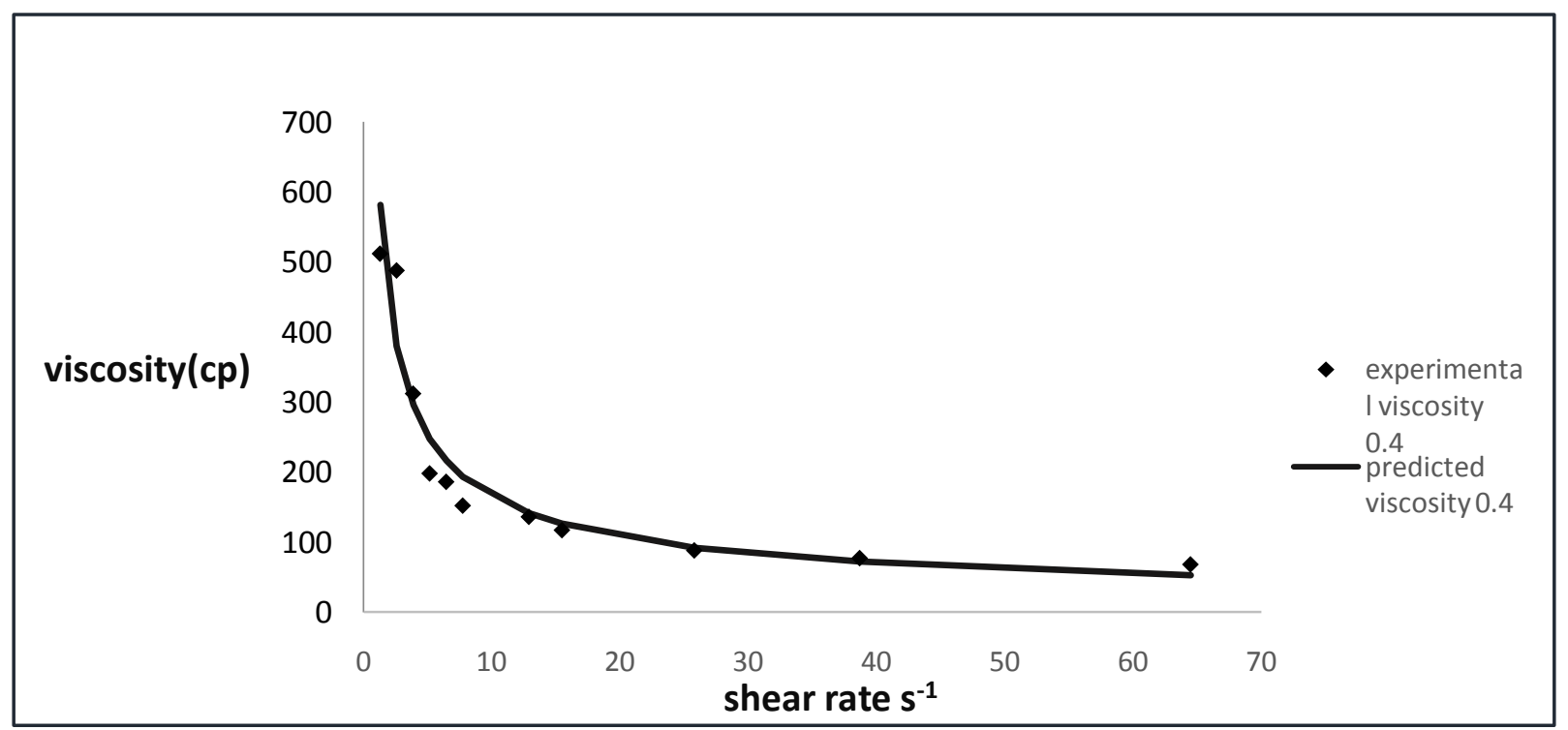

Fig. 9:- The relation between predicted and experimental data for the viscosity versus shear rate for $4000 \mathrm{ppm}$ PAM solution. 


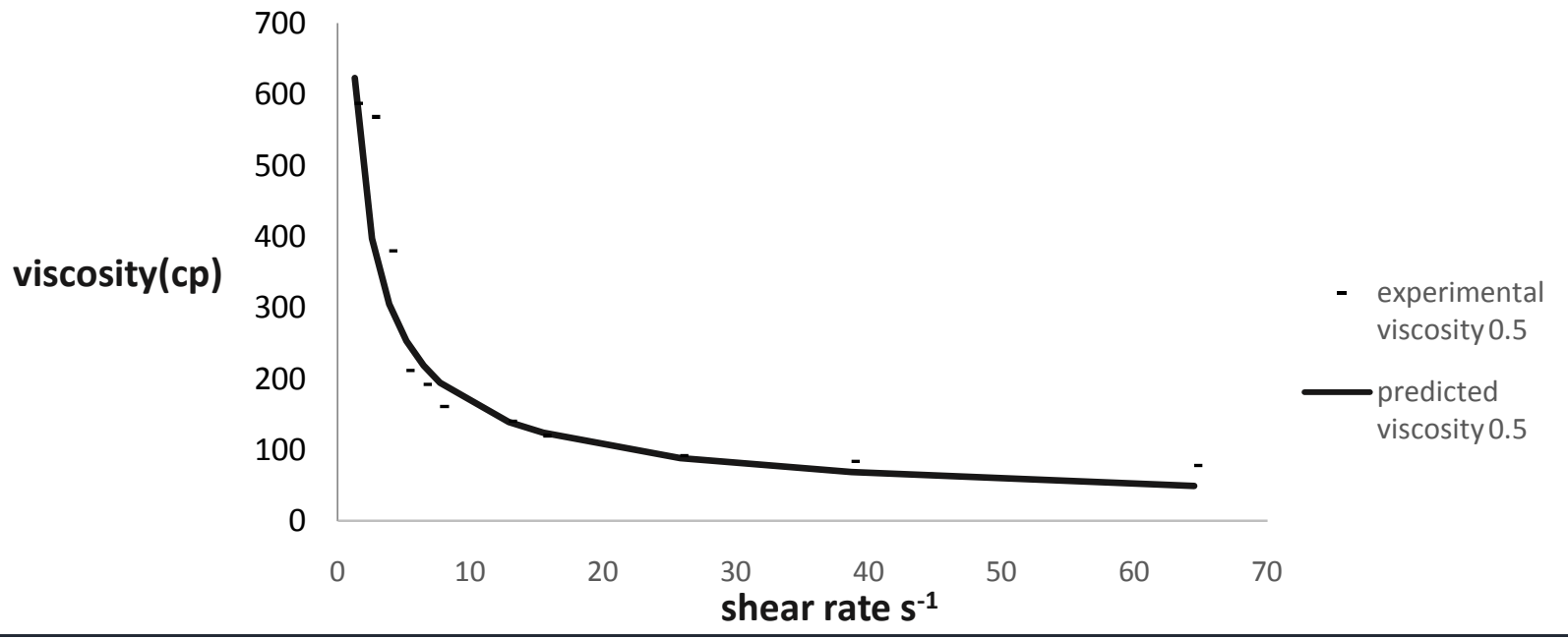

Fig. 10:- The relation between predicted and experimental data for the viscosity versus shear rate for $5000 \mathrm{ppm}$ PAM solution.

\section{Conclusion:-}

From these figures we can conclude that:

1. The polyacrylamide solutions showed strong shear thinning behavior for all concentrations

2. For the same temperature and concentration the viscosity varies exponentially with the shear rate.

3. The drop in viscosity is very sharp as shear rate increases slightly at low levels of shear rate. This sensitivity vanishes rapidly at the higher values of shear rate.

4. As the PAM concentration increases, the apparent viscosity of the solution increases

\section{Reference:-}

1. Atesok, G., P.Somasundaran, and L.J.Morgan(1988),'Charge Effects in the absorption of polyacrylamides on sodium kaolinite and its flocculation',powder technology,54pp77-83.

2. Ait-Kadi, A. Cameau, P. J. and Chauveteau, G.,(1987) ' Rheological Properties of Partially Hydrolyzed Polyacrylamide Solutions 'Journal of Rheology, 31(7), 537. 1987.

3. Bird, R.B., and Armstrong, R. Dynamics of Polymeric Liquids 1. John Wiley and Sons Inc., New York. 1987.

4. Bird, R.B., Steward, W.E. and Lightfoot, E.W., Transport Phenomena, John Wiley \& Sons, Inc., New York (1960).

5. Bradna, P., Quadrat, O. and Dupuis, D.(1995)' The influence of salt concentration on negative thixotropy in solutions of partially hydrolyzed Polyacrylamide' Colloid Polym. Sci. 273, PP421-1995

6. Dupuis, D., Lewandowski, F. Y., Steiert, P. and Wolff, C. (1994)' Shear thickening and time-dependent phenomena: the case of polyacrylamide solutions ' non-Newtonian Fluid Mech. 54, PP11-32 1994.

7. Durst, F., R. Hass, and Kaczmar, B. U. J.(1981)' Flows of dilute hydrolyzed polyacrylamide solutions in porous media under various solvent conditions ' Applied PolyrnSci.,26, 3125- 3149.1981.

8. Esmail, M. N., and Ghannam, M. T.,(1998)'Rheological properties of aqueous polyacrylamide solutions' J. Appl. Polym. Sci., 69, 1587-1597. 1998

9. Flew, S. and Sellin, R. H.(1993),' Non-Newtonian flow in porous media-a laboratory study of Polyacrylamide solutions ' J. Non-Newtonian Fluid Mech., 47,169. 1993.

10. Ghimici L., Popescu F.,(1998)' Determination of intrinsic viscosity for some cationic polyelectrolytes by Fedors method ' J. Euro. Polym., 34 (1998) 13.

11. Kitano T., Hashmi S.A.R., Chand N., Bull(2004).'influence of steady shear flow on dynamic viscoelastic properties of un-reinforcedand Kevlar glass fiber reinforcedLLDPE' Matter Sci., 27(5) (2004) PP409-415.

12. Lake, P.S.(2008)' Flow-Generated disturbances and Ecological Responses: Floods and Droughts. In Hydroecology and Ecohydrology: Past, Present and Future; Wiley Press' New York, NY, USA, 2008; pp. 7592.

13. Lee L.T., Rahbari R., Lecourtier J., Chauveteau G.(1991),'adsorption of polyacrylamides on different faces of kaolinites' J. Colloid. Inter. Sci., 147 pp351-357 
14. Mansri A., Tennouga L., Desbrières J.(2007), 'Viscosimetric behaviour of hydrolyzed polyacrylamide-poly(4vinylpyridine) [AD37-P4VP] mixture in aqueous solution' J. Eur. Polym., 43 pp540-549.

15. Nasr-El-Din, H. A., and Taylor, K. C.,(1993)' Interfacial behaviour of crude oil/alkali systems in the presence of partially hydrolysed polyacrylamide' Colloid and Surfaces A: Physicochemical and Engineering Aspects, 75, 169. 1993.

16. P. Bradna, O. Quadrat, D. Dupuis,(1995)' The influence of salt concentration on negative thixotropy in solutions of partially hydrolyzed Polyacrylamide ' J. Colloid Polym. Sci., 273, 421. 1995

17. Pefferkorn E.N., Carroy A.,(1985)'Adsorption of polyacrylamide to Na kaolinite: Correlation between clay structure and surface properties' J. Colloid. Inter. Sci., 106 (1985) 94.

18. Picout, D.R.; Ross-Murphy, S.B.(2003)' Rheology of biopolymer solutions and gels'. Sci. World J. 2003, 3, $105-121$.

19. Tie-Qiang, L. and Mc Cathy, K. L.(1995)' Pipe flow of aqueous polyacrylamide solutions studied by means of nuclear magnetic resonance imaging' J. non-Newtonian Fluid Mech., 57, 155.1995.

20. Wu Q., Shangguan Y., Zhou J., Song Y., Zheng Q.,(2009) Steady and dynamic rheological behaviors of sodium carboxymethyl cellulose entangled semi-dilute solution with opposite charged surfactant dodecyltrimethylammonium bromide J. Collo. Inter. Sci., 339 (2009) 236.

21. Ydens I., Moins S., Degée P., Dubois P.(2005), Solution properties of well-defined 2-(dimethylamino)ethyl methacrylate-based (co)polymers: A viscometric approachJ. Euro. Polym., 41 (2005) 1502. 